Article

\title{
Influence of Electrostatic Interactions During the Resorcinol-Formaldehyde Polymerization on the Characteristics of Mo-Doped Carbon Gels
}

\author{
Sergio Morales-Torres $\mathbb{D}^{\mathbb{D}}$, Hana Jirglová, Luisa M. Pastrana-Martínez $\mathbb{D}$ and \\ Francisco J. Maldonado-Hódar*(D) \\ Department of Inorganic Chemistry, Faculty of Sciences, University of Granada, Avda. Fuente Nueva, s/n., \\ ES18071 Granada, Spain; semoto@ugr.es (S.M.-T.); hana.jirglova@jh-inst.cas.cz (H.J.); \\ lpastrana@ugr.es (L.M.P.-M.) \\ * Correspondence: fjmaldon@ugr.es; Tel.: +34-958240444
}

Received: 9 June 2020; Accepted: 23 June 2020; Published: 26 June 2020

\begin{abstract}
The resorcinol (R)-formaldehyde (F) polymerization was carried out in different experimental conditions to obtain RF/Mo doped carbon xerogels with different morphology, porosity and nature and dispersion of metal. Attractive or repulsive electrostatic interactions were forced in the starting aqueous solution of RF-monomers using different synthesis conditions, namely, combinations of cationic or anionic surfactants, Mo-precursors and $\mathrm{pH}$ values. The results showed that when both cationic surfactant and Mo-precursor were used at neutral $\mathrm{pH}$, attractive interactions with the anionic RF-macromolecules are favored during polymerization and the final carbon xerogel exhibited the most developed porosity and the strongest Mo-organic phase interaction, leading to deeper Mo-phase reduction during carbonization and the formation of highly-dispersed crystalline nanoparticles of $\mathrm{Mo}_{2} \mathrm{C}$. On the contrary, the use of both anionic surfactant and Mo-precursor leads to repulsive interactions, which generates less porous carbon gels with a Mo-phase formed by large $\mathrm{MoO}_{3}$ platelet structures and low Mo-surface contents. RF/Mo-doped gels with intermediate properties were obtained by combining cationic and anionic surfactants, metal precursors or both. After carbonization, the obtained materials would be suitable to be used directly as catalysts with different physicochemical properties and active phases.
\end{abstract}

Keywords: resorcinol-formaldehyde polymerization; surfactants; Mo-doping; chemical interactions; carbon xerogels; physicochemical properties; metal nanoparticles

\section{Introduction}

The sol-gel process is an important synthesis method for the development of nanostructured materials with different applications [1-3]. The great advantage of the sol-gel synthesis is the ability to fit the properties and nanostructure of materials by properly combining the synthesis conditions and the interactions between the different components. Carbon gels (such as, aero-, xero- or cryogels) can be obtained in different formats and with different micro/nanostructure from a wide number of monomers, although they are commonly prepared from resorcinol-formaldehyde (R-F) polymerization [4-8]. That reaction is typically catalyzed by weak bases $\left(\mathrm{Na}_{2} \mathrm{CO}_{3}\right)$ and starts with the formation of anions by deprotonation of the $\mathrm{R}$ molecule [8-10] favoring the subsequent $\mathrm{F}$ addition and then, the crosslinking in the RF-macromolecule for the formation of the organic gel. In acidic media, reactions take place with the formation of carbocations by protonation of $\mathrm{F}$ molecules [11,12].

The control of the porous structure of carbon gels is strongly important when these materials are designed to be used as adsorbents or catalysts. The structure of these materials consists of a 3D-network 
of spherical particles, leaving between them large volumes of macro or mesopores $[5,10,12]$. The size and arrangement of the primary particles, and consequently the macro-mesoporous structure of the samples, is controlled during the sol-gel process and determined by the composition of the starting solution (i.e., monomer, catalyst or solvent nature and concentration) or synthesis conditions (i.e., $\mathrm{pH}$, temperature), and should be preserved during the drying process [10], supercritical drying being the best option to avoid the collapse of the porous structure. Microporosity is developed inside the primary particles during the carbonization, activation or both processes, by the release of pyrolysis gases and it is influenced by parameters such as, temperature, atmosphere or soak time.

Surfactants (S) can also be used as template or shape-directing agents of carbon gels [13-17]. The electrostatic interactions between the components of the starting solutions change depending on surfactant nature (cationic, anionic or non-ionic) [13-17]. The surfactant molecules can be incorporated into the RF-chemical structure forming RFS composites depending on the surfactant nature $[15,16]$. The micellar geometry is also influenced by parameters like, the $\mathrm{pH}$ value due to the protonation/deprotonation of acidic/basic groups, co-surfactants or metal precursors [18,19].

In order to improve the application of carbon gels in catalysis, an appropriate control of the porous texture, together with the development of specific active sites is needed. Carbon gels can be chemically modified with different strategies including the introduction of heteroatoms (i.e., N, B, S, P, O), but mainly metallic active phases $[7,20,21]$. When heterogeneous catalysts based on metallic compounds are developed, the active phases can be supported by classical deposition or impregnation methods [21], but also by doping the starting solutions of organic monomers with the soluble metal precursors [22], directly obtaining suitable metal-doped carbon gels to be used as catalysts. Both procedures have advantages and drawbacks which have been reported [5,23].

In our previous manuscripts $[4,5,16,23,24]$, different series of heterogeneous catalysts based on carbon gels were prepared in different formats (powders, pellets, coatings, etc.) either by doping or impregnation with metal precursors. When metal precursors are solubilized in the starting solutions, ions can induce additional electrostatic interactions with the charged R-F intermediates $[25,26]$, which determine the sol-gel transition, namely the primary particle size and packing and consequently, the morphology and textural properties of the RF organic gel. These parameters change as a function of the polarizing power of the counter ions, when even low amounts of different alkaline carbonates $\left(\mathrm{M}_{2} \mathrm{CO}_{3}\right.$, $\mathrm{M}=\mathrm{Li}, \mathrm{Na}, \mathrm{K}, \mathrm{Rb}, \mathrm{Cs}$ ) are used as polymerization catalysts [26]. The pore size distribution changes from narrow mesopores to macropores, with increasing the alkali cation size. Larger effects are provoked using transitions metals and/or high metal loadings [22,25]. In addition, metallic nanoparticles are formed during the synthesis procedure interacting with the organic fraction and also undergo changes according the experimental conditions of these steps (polymerization, carbonization/activation, graphitization), which determine the dispersion and nature of the metallic phases, and their catalytic performance consequently [22,24].

When surfactants and metal precursors are combined in the starting solutions, interactions become progressively more complex. Inorganic ions are believed to link with the hydrophilic head group of the surfactant molecule, modifying the characteristics of the micelle [27]. The morphology of the organic RF-polymer, the nature, shape, size and distribution of the metallic nanoparticles, as well as the transformation during thermal treatment, including graphitization [28] or carburization [17] processes, depend on the balance of these electrostatic interactions and the possible links between phases $[16,17,28]$. There are only a few references in this regard.

Molybdenum was selected as active phase in the corresponding catalysts because of their good performance in different environmental or energetic catalytic processes [29,30].

The aim of this work is to prepare a series of Mo-catalysts by polymerization of RF by adding a cationic $\left(\mathrm{Mo}^{5+}\right)$ or anionic $\left(\mathrm{MoO}_{4}{ }^{2-}\right)$ metallic phase (Mo) to the starting RF solution in presence of a cationic (hexadecyltrimethylammonium bromide, CTAB) or anionic (sodium dodecyl benzene sulfonate, DCBS) surfactant at different $\mathrm{pH}$ values. The Mo-loading was of $1 \mathrm{wt} \%$ regarding reactant $(\mathrm{R}+\mathrm{F})$. The influence of these combinations on the development of the sol-gel process, the subsequent 
transformations during carbonization and consequently, the final physicochemical properties of Mo-doped carbon xerogels were analyzed by several characterization techniques.

\section{Materials and Methods}

\subsection{Preparation of Mo-Supported Carbon Xerogels}

The synthesis procedure was similar to that reported in a previous manuscript [17], involving the preparation of a starting mixture of resorcinol (R) and surfactant (S) in water (W). As surfactants, anionic DCBS or cationic CTAB (99\%, both supplied by Sigma-Aldrich, St. Louis, MO, USA) were employed in the presence of tert-butanol (t-BuOH, 99.5\%, supplied by Acros Organics, Geel, Belgium) and 1,3,5-trimethyl benzene (TMB, supplied by PanReac AppliChem, Darmstadt, Germany) as pore-swelling agents. The $\mathrm{pH}$ of solutions was adjusted at ca. 7 and 10 by the addition of $\mathrm{NaOH}$ ( $99 \%$, supplied by Acros Organics, Geel, Belgium) or $\mathrm{pH}$ ca. 5 without the addition of $\mathrm{NaOH}$, to analyze the influence of this parameter. This mixture is heated up to $50{ }^{\circ} \mathrm{C}$ under reflux and vigorous stirring. The polymerization starts immediately in these conditions with the addition of $\mathrm{F}$, but is maintained for $2 \mathrm{~h}$ to guarantee the complete polymerization and gelation of reactants. Afterwards, another aqueous solution of the selected metal precursor was dropped on the gel dispersion. Ammonium heptamolybdate tetrahydrate $\left(\left(\mathrm{NH}_{4}\right)_{6} \mathrm{Mo}_{7} \mathrm{O}_{24} \cdot 4 \mathrm{H}_{2} \mathrm{O}, 99.9 \%\right.$, supplied by Sigma-Aldrich, St. Louis, MO, USA) and molybdenum (V) chloride $\left(\mathrm{MoCl}_{5}, 99.9 \%\right.$, supplied by Sigma-Aldrich, St. Louis, MO, USA) were used as anionic and cationic Mo-precursors, respectively. After Mo-doping, the temperature of dispersion was increased to $90^{\circ} \mathrm{C}$ and maintained for $24 \mathrm{~h}$ to complete the polymer curing. Then, the suspension was cooled down to room temperature and the solid product filtered and washed with distilled water and ethanol, to remove un-reacted reagents. The wet product was dried at atmospheric pressure, first at $50^{\circ} \mathrm{C}$ for $12 \mathrm{~h}$ and finally, at $120^{\circ} \mathrm{C}$ for $12 \mathrm{~h}$. Resulting Mo-doped organic xerogels were carbonized under nitrogen flow $\left(100 \mathrm{~cm}^{3} / \mathrm{min}\right)$ in a tube furnace, using a heating rate of $2{ }^{\circ} \mathrm{C} / \mathrm{min}$ up to $900^{\circ} \mathrm{C}$ and a soaking time of $5 \mathrm{~h}$. The materials were labeled as "MoX-SY-pHZ", where " $\mathrm{X}$ " indicates the type of metal precursor, i.e., " $\mathrm{A}$ " for anionic $\mathrm{MoO}_{4}{ }^{2-}$ and " $\mathrm{C}$ " for cationic $\mathrm{Mo}^{5+}$; " $\mathrm{Y}^{\text {" }}$ stands the type of surfactant, i.e., " $\mathrm{A}$ " for anionic DCBS and " $\mathrm{C}$ " for cationic CTAB; and " $\mathrm{Z}$ " marks the $\mathrm{pH}$ value of the synthesis (i.e., 5, 7 and 10). In addition, a sample without any surfactant (MoA-pH7) was prepared for comparison. The composition (in molar ratio) of the starting solutions was in all cases: $\mathrm{R} / \mathrm{F}=\frac{1}{2}, \mathrm{R} / \mathrm{W}=1 / 180, \mathrm{R} / \mathrm{S}=\frac{1}{2}, \mathrm{R} / \mathrm{TMB}=\frac{1}{2}$ and $\mathrm{R} / \mathrm{t}-\mathrm{BuOH}=1 / 1$.

\subsection{Catalysts Characterization}

The obtained Mo-supported carbon xerogels were textural and chemically characterized by several techniques. The carbonization processes were simulated by thermogravimetry (TG) using a thermobalance model TGA-50H (Mettler-Toledo International Inc., Greifensee, Switzerland). Experiments were carried out in $\mathrm{N}_{2}$ flow and $10{ }^{\circ} \mathrm{C} / \mathrm{min}$. The chemical nature and dispersion of the Mo-phase were analyzed by X-ray diffraction (XRD), X-ray photoelectron spectroscopy (XPS) and high-resolution transmission electron microscopy (HRTEM). XRD measurements were carried out using a Bruker D8 Advance diffractometer (BRUKER, Rivas-Vaciamadrid, Spain) and the corresponding XRD-patterns analyzed on the basis of JCPDS files. The morphology of the carbons was observed by scanning electron microscopy (SEM) using a Leo Carl Zeiss (Geminy-153, Oberkochen, Germany) microscope. HRTEM images were obtained with an HAADF FEI TITAN G2 microscope (Oberkochen, Germany). These images were used for the analysis of the particle size and dispersion. X-ray photoelectron spectroscopy (XPS) measurements were made by a Kratos Axis Ultra-DLD (Analytical Ltd, Kyoto, Japan), equipped with MgK X-ray source (hv = $1253.6 \mathrm{eV})$. Survey and multi-region spectra were recorded at C1s, O1s and Mo3d photoelectron peaks. Each spectral region of photoelectron interest was scanned several times to obtain good signal-to-noise ratios. The spectra were fitted to Lorentzian and Gaussian curves in order to obtain the number of components, and the position and area of the peaks. 
The textural properties of carbon xerogels were determined by physical adsorption of $\mathrm{N}_{2}\left(-196^{\circ} \mathrm{C}\right)$ and $\mathrm{CO}_{2}\left(0^{\circ} \mathrm{C}\right)$ using an Autosorb-1 Quantachrome equipment (Boynton Beach, FL, USA). The BET surface areas $\left(S_{\mathrm{BET}}\right)$ were obtained by applying the BET equation to the $\mathrm{N}_{2}$-adsorption isotherms. Further information about the microporosity of the samples, the micropore volume $\left(W_{0}\right)$ and mean micropore width $\left(L_{0}\right)$ values were obtained by using the Dubinin-Radushkevich (DR) and Stoeckli equations, respectively [31]. The total pore volume $\left(V_{\mathrm{T}}\right)$ was obtained considering the volume of $\mathrm{N}_{2}$ adsorbed at $\mathrm{P} / \mathrm{P}_{0}=0.95$, whilst the mesopore volume $\left(V_{\text {meso }}\right)$ from the difference between $V_{\mathrm{T}}$ and the volume adsorbed at $\mathrm{P} / \mathrm{P}_{0}=0.40$ by application of the Gurvich rule.

\section{Results and Discussion}

The development of metal-doped carbon xerogels for catalytic applications aims the control of the porous texture of the carbon supports, the chemical nature and dispersion of the supported metal-phase as well as the interactions between both phases. We developed a synthesis procedure of metal-doped carbon xerogels in order to avoid some of the metal nanoparticles possibly being trapped by the organic matrix. Because the network structure of the polymeric gel is previously formed, the metal particles can be formed only in the surface. Nevertheless, impregnation is carried out before curing with the aim to avoid long aging or high temperature treatment, thus preserving the reactivity of the surface groups on the polymeric surface of the gel previously formed and favoring the Mo-anchoring. For that purpose, the experimental conditions of each synthesis step should be controlled. The morphology of the samples is defined during polymerization, although shrinkage occurs during drying and carbonization, defining the macro-meso structure of the samples. However, the thermal treatments induce the development of the microporosity, as a consequence of the release of the pyrolysis gases, and the transformations of both organic and metallic phases $[5,28]$.

The chemical structure of the organic gels was analyzed by XPS. Each spectral region was de-convoluted and the atomic surface composition quantified. Results are collected in Table 1 for the prepared samples at $\mathrm{pH}=7$. It is noteworthy that the surface Mo-content strongly depends on the cationic or anionic character of surfactants and Mo-precursors. The Mo-loading obtained is lower using the anionic surfactant, but also the anionic metal precursor regarding the cationic one, which denotes the importance of the electrostatic interactions in the doping process. The presence of heteroatoms ( $\mathrm{N}$ or $\mathrm{S}$ ) also confirms the incorporation of the surfactant molecules (CTAB and DCBS, respectively) to the chemical structure of the organic gels.

Table 1. Atomic surface composition of Mo-doped xerogels obtained by XPS analyses before and after carbonization.

\begin{tabular}{cccccc}
\hline Sample & \%C at. & \%O at. & \%Mo at. & \%N at. & \%S at. \\
\hline Organic samples & & & & & \\
MoA-SC-pH7 & 79.9 & 15.7 & 2.4 & 2.0 & - \\
MoC-SA-pH7 & 81.9 & 14.7 & 0.3 & - & 3.1 \\
MoC-SC-pH7 & 68.5 & 20.8 & 7.7 & 3.0 & - \\
Carbonized samples & & & & & \\
MoA-SA-pH7 & 88.8 & 10.6 & 0.6 & - & - \\
MoA-SC-pH7 & 91.3 & 5.4 & 3.3 & - & - \\
MoC-SA-pH7 & 83.1 & 12.1 & 1.0 & - & 3.8 \\
MoC-SC-pH7 & 88.7 & 9.1 & 2.2 & - & - \\
\hline
\end{tabular}

The components of each spectral region were fitted and assigned according to the literature. The C1s XPS spectra for both MoC-SC-pH7 and MoC-SA-pH7 are shown in Figure 1a,b, respectively. Three components were used to deconvolute the $\mathrm{C} 1 \mathrm{~s}$ core level spectra for these organic polymers [32]. The main C1s component is observed at a binding energy (BE) of $\approx 286.9 \mathrm{eV}$, corresponding to C-O bonds of aliphatic methylene ether bridges between aromatic rings and unreacted hydroxyl groups of the phenolic monomers [10], together a smaller contribution of the aromatic and aliphatic $\mathrm{C}=\mathrm{C}$ bonds at $\approx 285.0 \mathrm{eV}$ and $\mathrm{C}=\mathrm{O}$ bonds at $\approx 288.4 \mathrm{eV}$. It is also noteworthy that the peak of MoC-SA-pH7 is 
quite symmetric, while that corresponding to MoC-SC-pH7 presents a marked shoulder at $\approx 288.4 \mathrm{eV}$ denoting a higher concentration of $\mathrm{C}=\mathrm{O}$ bonds.
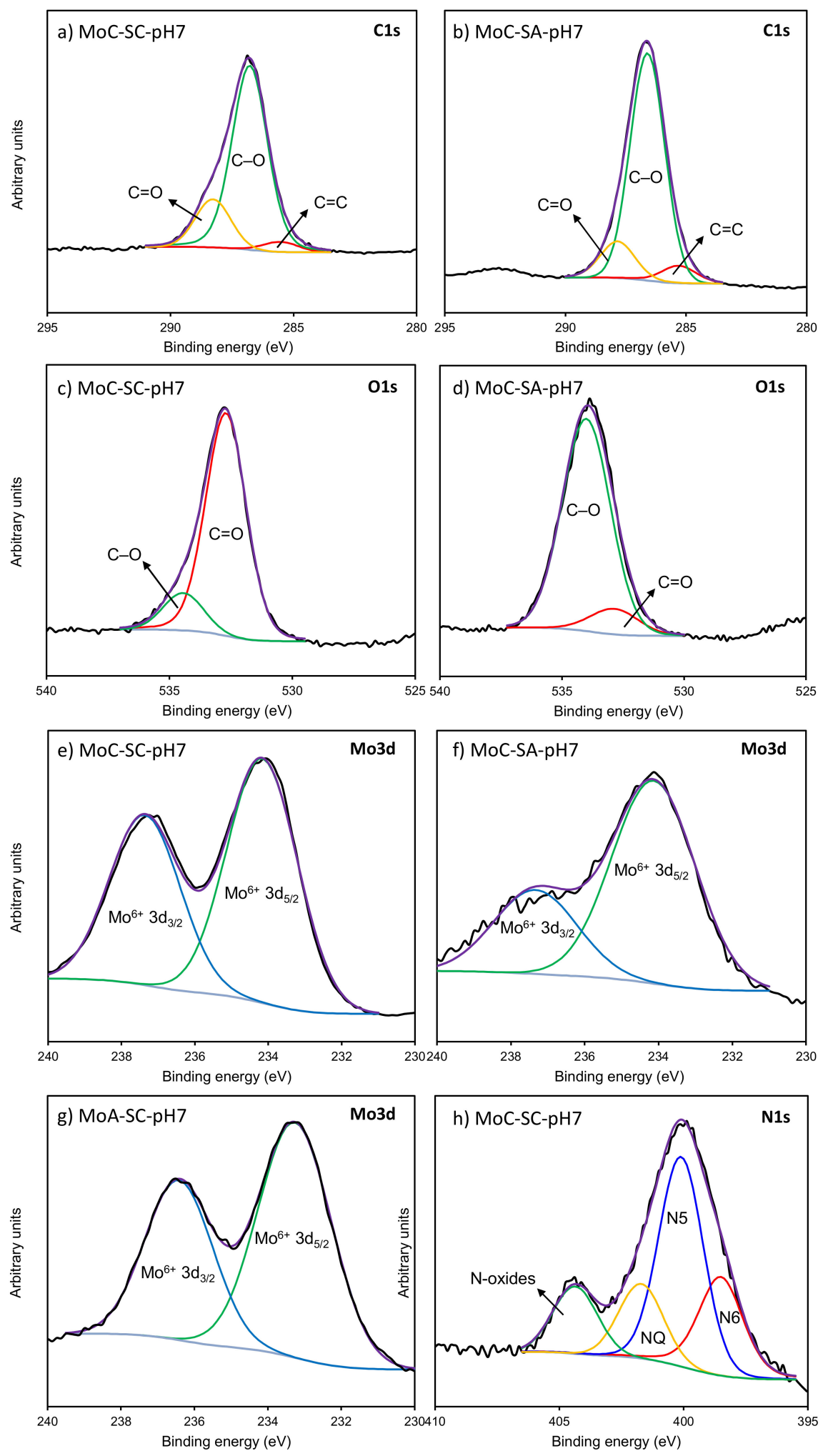

Figure 1. Analysis of the C1s (a,b), O1s (c,d), Mo3d (e-g) and N1s (h) high resolution XPS core-level spectra of Mo-doped organic gels. 
The O1s spectral region was fitted using two components associated to the organic phase (MoC-SC-pH7 and MoC-SA-pH7 in Figure 1c and d, respectively). The pure $\mathrm{MoO}_{3}$ exhibits a sharp $\mathrm{O} 1 \mathrm{~s}$ peak at $\mathrm{BE} \approx 530.6 \mathrm{eV}$ [33], but this signal is negligible at these $\mathrm{BE}$ values. Thus, the oxygen content is mainly due to the organic phase, the first component at $\approx 532.7 \mathrm{eV}$ is assigned to the $\mathrm{C}=\mathrm{O}$ bonds and the second one at $\approx 534.3 \mathrm{eV}$ to the C-O ones [32]. In the MoC-SC-pH7 polymer the maximum of the O1s profile is located at $\approx 532.6 \mathrm{eV}$, while in case of MoC-SA-pH7 is observed at $\approx 534.1 \mathrm{eV}$, denoting the preferential $\mathrm{C}=\mathrm{O}$ bonds over $\mathrm{C}-\mathrm{O}$ bonds are more abundant in the second one, which is in agreement with the previous $\mathrm{C} 1 \mathrm{~s}$ spectral region fitting. As commented, the presence of heteroatoms on the organic gel structure due to the incorporation of the corresponding surfactants was also detected. In the case of CTAB (MoC-SC-pH7, Figure 1h) the N-signal is enough to analyze the N1s core level spectra showing the formation of different N-surface groups, such as, N-pyridinic (N6), N-pyrrolic (N5), N-quaternary (NQ), which were also identified according to the literature [34].

The Mo3d XPS spectra for MoC-SC-pH7, MoC-SA-pH7 and MoA-SC-pH7 are shown in Figure 1e-g, respectively. The region Mo3d was also fitted using two components. The $\mathrm{Mo}^{6+}$ in $\mathrm{MoO}_{3}$ presents a characteristic $\mathrm{d}_{5 / 2}$ and $\mathrm{d}_{3 / 2}$ doublet at $\approx 232.9$ and $\approx 236.0 \mathrm{eV}$, respectively, with a separation between peaks of $3.2 \mathrm{eV}$ [35], in good agreement with the results obtained for MoA-SC-pH7 (Figure 1g), where the Mo3d $\mathrm{d}_{5 / 2}$ and $\operatorname{Mo}_{3 / 2}$ components are centered at $\approx 233.3$ and $\approx 236.4 \mathrm{eV}$, respectively. When cationic $\mathrm{Mo}^{5+}$ was used as precursor, the analysis indicates that $\mathrm{Mo}^{5+}$ was oxidized during the sol-gel synthesis, being as $\mathrm{Mo}^{6+}$ in both MoC-SC-pH7 and MoC-SA-pH7 samples (Figure 1e,f, respectively). Moreover, in both cases, the Mo3 $\mathrm{d}_{5 / 2}$ and Mo3 $\mathrm{d}_{3 / 2}$ components are centered at $\approx 234.2$ and $\approx 237.3 \mathrm{eV}$, respectively, at $\mathrm{BE}$ even higher than those expected for $\mathrm{Mo}^{6+}$. These results indicate a different chemical environment of the Mo-nanoparticles and different interactions between the Mo-organic phases. Previous studies showed that when $\mathrm{MoO}_{3}$ is supported on organic polymers, electronic transfers between phases significantly modify the position of the XPS peaks in the different spectral regions [36].

The carbonization process was simulated by TG, as summarized in Figure 2. Typically, the carbonization of RF-organic gels is complete after $650-700{ }^{\circ} \mathrm{C}$. TG curves showed the main weight loss between $300-400^{\circ} \mathrm{C}$ associated with the breaking and release of weaker methylene and methylene-ether links between aromatic rings of the RF chemical structure, with a second step between $450-600{ }^{\circ} \mathrm{C}$, where the breakage of $\mathrm{C}-\mathrm{H}$ bonds and the formation of $\mathrm{C}-\mathrm{C}$ ones occur $[9,16]$. Figure 2a shows the influence of the surfactant nature on the transformation of chemical structure of $\mathrm{Mo}^{5+}$ doped samples (i.e., MoC-SA-pH7 and MoC-SC-pH7 samples). When using anionic surfactant (MoC-SA-pH7) there is a certain initial weight loss below $100^{\circ} \mathrm{C}$ due to the loss of solvent and unreacted products, although the main decomposition process occurs at $\approx 420^{\circ} \mathrm{C}$. Moreover, a small shoulder is formed at $\approx 320^{\circ} \mathrm{C}$, and finally, another weight loss at around $650^{\circ} \mathrm{C}$. The differential thermogravimetric (DTG) profile obtained for the MoC-SC-pH7 sample, prepared using cationic surfactant, showed the main weight loss also at around $\approx 420^{\circ} \mathrm{C}$, mainly denoting a similar bond breakage and thermal stability of the RF-structure; however, other significant weight loss can be observed at $\approx 240^{\circ} \mathrm{C}$ and $\approx 810^{\circ} \mathrm{C}$ regarding the MoC-SA-pH7 sample. The first one is due to the decomposition of the groups generated by the incorporation of the CTAB surfactant into the chemical structure of RF-gel, which decompose at this temperature range [16]. The last sharp DTG-peak at high temperature (ca. $810{ }^{\circ} \mathrm{C}$ ) can be associated with the reduction of the molybdenum oxide phases, as it will be discussed below. Using the combination of CTAB and $\mathrm{MoO}_{4}{ }^{2-}$ precursors to point out the influence of $\mathrm{pH}$ on the chemical stability (MoA-SC-pH7 and MoA-SC-pH5 samples, Figure 2b), it is observed that increasing pH of the starting solution, the DTG profile is maintained but the position of the main DTG bands are slowly shifted to higher temperatures, denoting some chemical reinforcement. This shifting could also be influenced by the different porosity of the samples which can determine the removal of the pyrolysis gases (Figure 2b). 

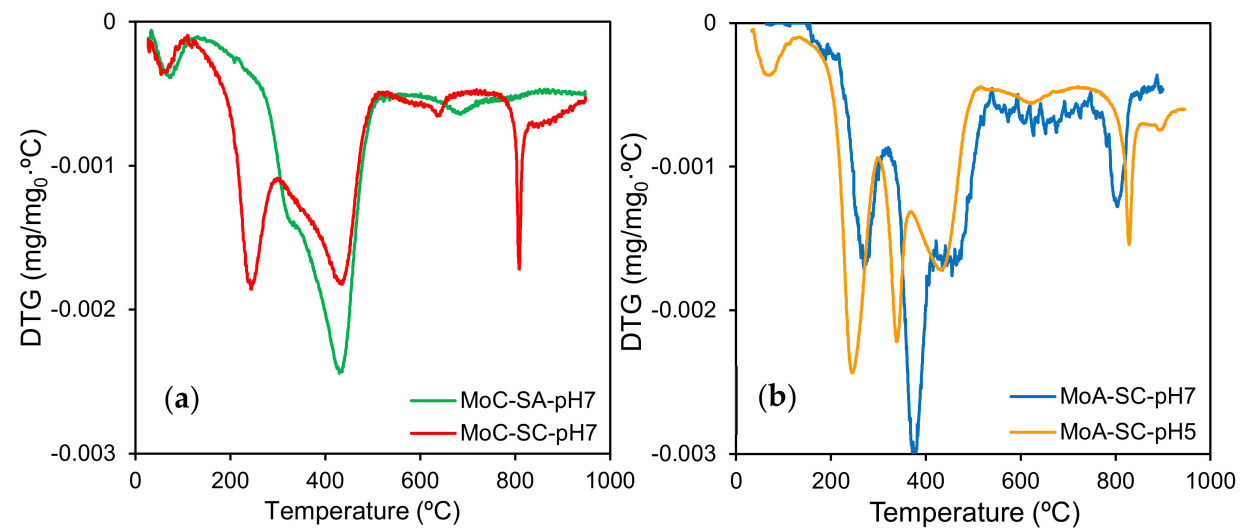

Figure 2. DTG-profiles obtained for the carbonization of organic xerogels: Influence of the (a) surfactant nature and $(\mathbf{b})$ the $\mathrm{pH}$ value.

The morphology of Mo-doped carbon xerogels were analyzed by SEM (Figure 3). The images pointed out the strong influences of the different combinations of cationic and anionic species in the starting solution. Materials obtained using the anionic surfactant (MoA-SA-pH7 and MoC-SA-pH7 samples, Figure 3a,b, respectively) are composed of big particles with a smooth and compact surface, regardless of the cationic or anionic nature of the metal precursor used. However, using the cationic surfactant, (MoC-SC-pH7, Figure 3d), the structure obtained resembles the typical RF structure [10], consisting in a network of highly interconnected spherical particles (primary particles formed during the sol state), leaving a developed porosity between them. This structure depends on the synthesis conditions, thus in the MoA-SC-pH7 sample (Figure 3c) the primary spherical particles can form filaments, while changing the $\mathrm{pH}$ of solution either to acidic (the MoA-SC-pH5 sample, Figure 3f) or basic (the MoA-SC-pH10 sample, Figure 3e), the primary particles are not observed, and in both cases the coalescence of these particles is favored forming larger structures that leave large macropores between them. In the case of MoA-SC-pH5, the acidic media also induces a greater coalescence of these structures leading to a continuous solid exhibiting a foam structure. Thus, a wide variety of morphologies were observed depending on the reactant combinations.

The change in the morphology of the samples that also influences their porous texture was analyzed by physical adsorption of $\mathrm{N}_{2}$ and $\mathrm{CO}_{2}$. The corresponding $\mathrm{N}_{2}$-adsorption isotherms of carbonized samples are recorded in Figure 4 and the textural parameters obtained from them are collected in Table 2. $\mathrm{CO}_{2}$ isotherms are shown in Figure S1a and b of the Supplementary Materials. In general, all isotherms correspond to the type IV associated to the mesoporous character of carbon gels. After the micropore filling at low $\mathrm{P} / \mathrm{P}_{0}$, the slope of the curve and the formation of a certain hysteresis loop denotes the formation of mesopores. The $\mathrm{CO}_{2}$ adsorption isotherms (not shown) provide information about the narrowest microporosity [37]. In all cases, there is a strong diffusion restriction to the narrowest microporosity, thus the micropore volume and the surface area determined from the $\mathrm{CO}_{2}$-adsorption isotherms are always larger than those obtained from the $\mathrm{N}_{2}$-isotherms (Table 2).

The porosity of the samples decreased in both acidic and basic media (MoA-SC-pH5 or MoA-SC-pH10), regarding neutral $\mathrm{pH}$ values (MoA-SC-pH7), as shown in Figure 4b. However, the volume of the narrowest micropores is favored by increasing the $\mathrm{pH}$ of the starting solution, although the mean micropore size is maintained at around $0.55 \mathrm{~nm}$, that is clearly inaccessible to $\mathrm{N}_{2}$ at $-196{ }^{\circ} \mathrm{C}$. Note that the mean micropore width $\left(L_{0}\right)$ determined by $\mathrm{N}_{2}$-adsorption is larger than $1.1 \mathrm{~nm}$ in all cases and that the mesopore volume $\left(V_{\text {meso }}\right)$ decreased regarding the sample obtained at neutral $\mathrm{pH}$ (MoA-SC-pH7), probably associated with the transformation of mesopores into micro and macropores in acidic or basic conditions, as previously denoted by SEM. These results are in agreement with those previously published [9,38]. Job et al. [38] obtained pure micro-mesoporous carbon materials at $\mathrm{pH}$ ranging from $5.5-6.3$, but this $\mathrm{pH}$ range changes in the presence of metals 
(Ni) to 6.5-7.3 for metal-doped carbon xerogels, but they obtained exclusively microporous materials in basic media, which showed a strong porosity reduction after carbonization, depending on metal and complexing agent.

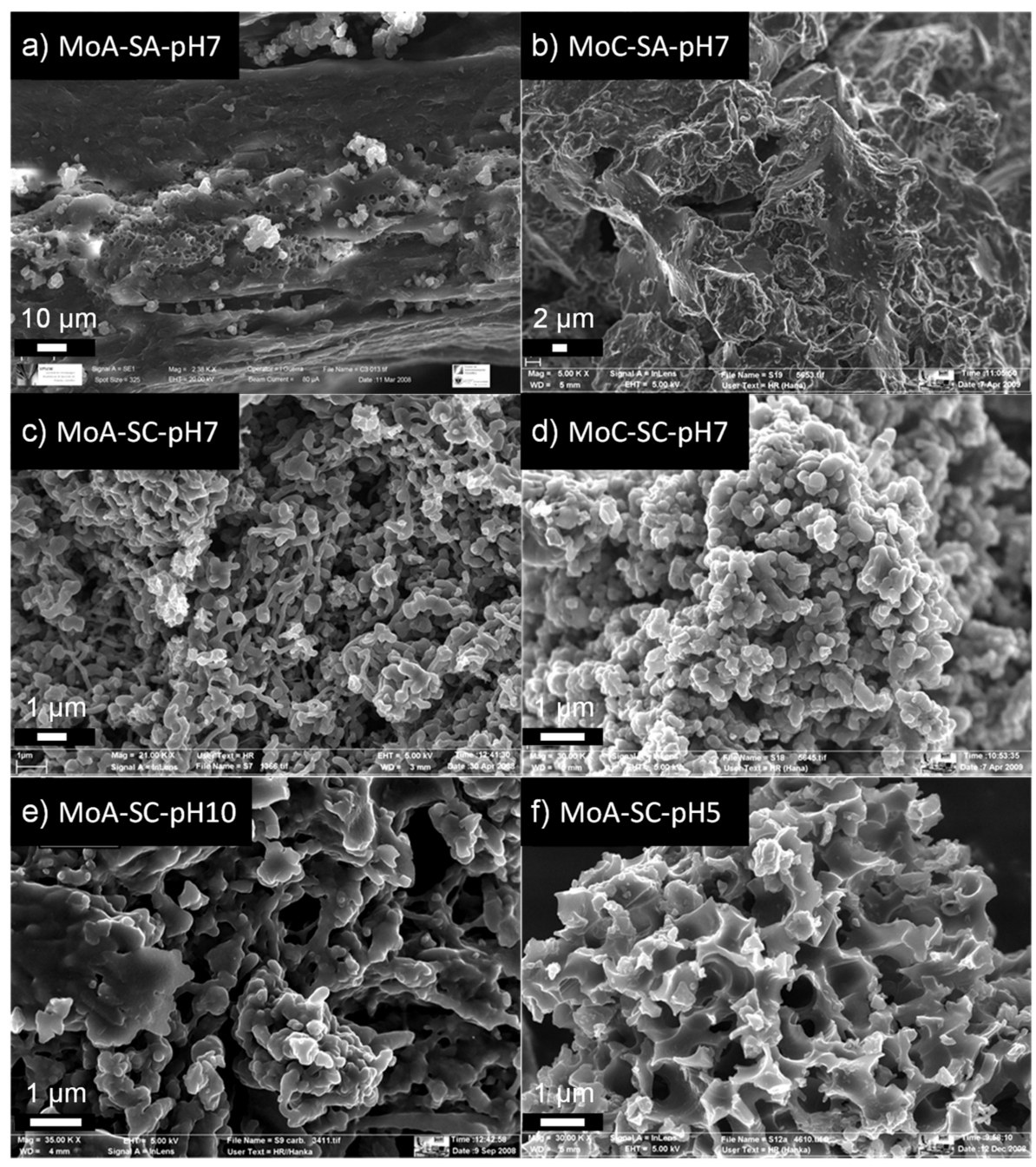

Figure 3. SEM images of Mo-doped carbon xerogels.
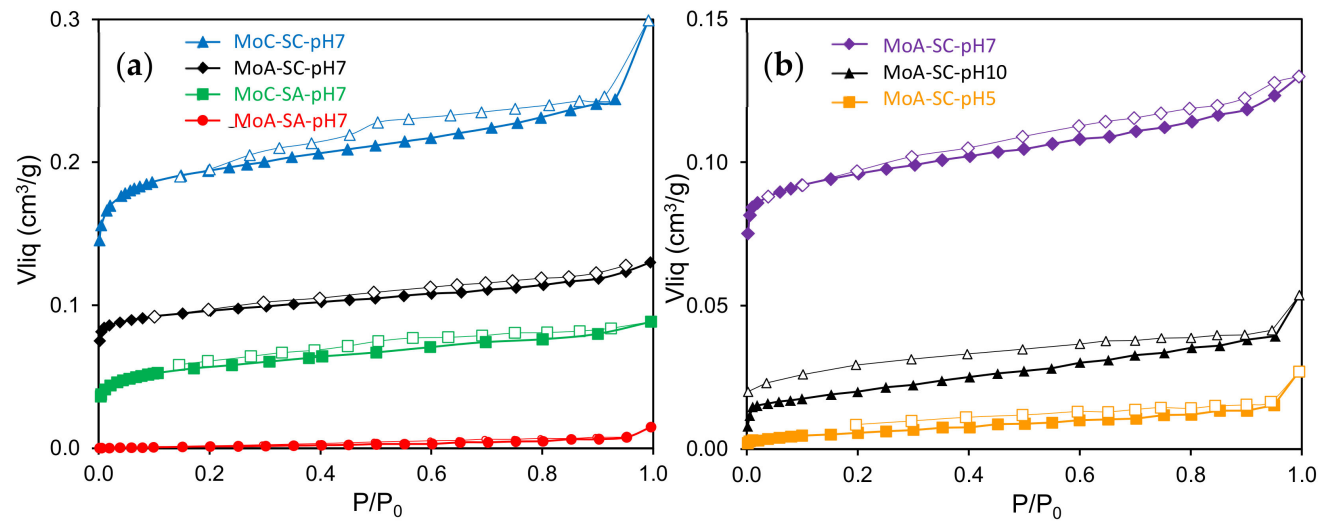

Figure 4. $\mathrm{N}_{2}$-adsorption isotherms showing the influence of (a) a combination of cationic and anionic surfactant and metal precursors and $(\mathbf{b})$ the $\mathrm{pH}$ value of the starting polymerization solutions. 
Table 2. Porous characteristics of metal-doped carbon xerogels.

\begin{tabular}{|c|c|c|c|c|c|c|c|c|}
\hline \multirow[b]{2}{*}{ Sample } & \multicolumn{5}{|c|}{$\mathrm{N}_{2}$-Adsorption } & \multicolumn{3}{|c|}{$\mathrm{CO}_{2}$-Adsorption } \\
\hline & $\begin{array}{c}S_{\mathrm{BET}} \\
\mathrm{m}^{2} / \mathrm{g}\end{array}$ & $\begin{array}{l}W_{0} \\
\mathrm{~cm}^{3} / \mathrm{g}\end{array}$ & $\begin{array}{c}L_{0} \\
\mathrm{~nm}\end{array}$ & $\begin{array}{c}V_{\mathrm{T}} \\
\mathrm{cm}^{3} / \mathrm{g}\end{array}$ & $\begin{array}{l}V_{\text {meso }} \\
\mathrm{cm}^{3} / \mathrm{g}\end{array}$ & $\begin{array}{l}S_{\mathrm{CO} 2} \\
\mathrm{~m}^{2} / \mathrm{g}\end{array}$ & $\begin{array}{c}W_{0} \\
\mathrm{~cm}^{3} / \mathrm{g}\end{array}$ & $\begin{array}{c}\mathrm{L}_{0} \\
\mathrm{~nm}\end{array}$ \\
\hline MoA-SC-pH5 & 14 & 0.004 & 1.8 & 0.027 & 0.007 & 481 & 0.130 & 0.54 \\
\hline MoA-SC-pH7 & 192 & 0.092 & 0.6 & 0.130 & 0.023 & 555 & 0.151 & 0.54 \\
\hline MoA-SC-pH10 & 45 & 0.017 & 1.1 & 0.054 & 0.027 & 682 & 0.194 & 0.57 \\
\hline MoC-SC-pH7 & 450 & 0.192 & 1.1 & 0.299 & 0.089 & nd & nd & nd \\
\hline MoA-SA-pH7 & 5 & - & - & 0.015 & 0.012 & 34 & 0.023 & 1.33 \\
\hline MoC-SA-pH7 & 136 & 0.054 & 2.2 & 0.088 & 0.018 & nd & nd & nd \\
\hline
\end{tabular}

MoC-SC-pH7 was the most porous sample obtained using the cationic surfactant and cationic metal precursor at neutral $\mathrm{pH}$. On the contrary, the less porous sample (i.e., MoA-SA-pH7), was obtained using both anionic surfactant and metal precursor. Intermediate behaviors were obtained using cationic surfactant and anionic metal precursor (MoA-SC-PH7) or anionic surfactant with cationic metal precursor (MoC-SA-pH7). As previously commented, the RF polymerization using soft basic catalysts, develops forming resorcinol anions which favor the F-addition reactions and consequently the crosslinking in the growing polymeric macromolecule. These results indicate that: (i) electrostatic interactions between the chemical species are important to control the crosslinking during the polymerization of RF, (ii) anionic species of the growing macromolecular polymer interact with the rest of the charged species in solutions, (iii) cationic species produce attractive interactions facilitating the incorporation into the molecular structure of the polymers (including surfactants and metallic phases, as previously denoted) and (iv) repulsive interactions with anionic species lead to non-porous samples with lower metal-loadings.

The chemical state and dispersion of the metallic phase in the carbonized samples were analyzed by DRX, XPS and HRTEM in order to analyze the transformations during carbonization and the stabilization of the corresponding Mo-active phases. The XRD-patterns of the carbonized samples are showed in Figure 5. The large bands at around $25^{\circ}$ and $42^{\circ}$ are due to the (002) and (101) diffractions of graphite and denote certain but poor ordering of the carbon support. Clearly, molybdenum possesses a weak influence on the graphitization of the carbon phase regarding other metals like Fe or Ni [28]. In general, no diffraction peaks corresponding to the Mo-phase were detected using molybdate species as metal precursor, only small peaks at $\approx 39.5$ and $\approx 61.7^{\circ}$, assigned to the most intense peaks of $\beta-\mathrm{Mo}_{2} \mathrm{C}$, are detected in MoA-SC-pH5. Nevertheless, in our previous studies, the formation of highly crystalline $\beta-\mathrm{Mo}_{2} \mathrm{C}$ in Mo-doped carbon xerogels was detected using MoA-SC combinations in acidic conditions, however, a higher $\mathrm{TMB} / \mathrm{t}-\mathrm{BuOH}$ concentration was used [16]. When cationic $\mathrm{CTAB}$ and $\mathrm{Mo}^{5+}$ were used (MoC-SC-pH7 sample), intense diffraction peaks at $\approx 34.4, \approx 37.9, \approx 39.5, \approx 52.2, \approx 61.7$ and $\approx 69.6^{\circ}$ corresponding to the (100), (002), (101), (110) and (103) planes of hexagonal $\beta-\mathrm{Mo}_{2} \mathrm{C}$ (JCPDS 35-0787) were observed, denoting the high crystallinity of this phase [35]. Nevertheless, none of the possible intermediate molybdenum oxides $\left(\mathrm{MoO}_{\mathrm{x}}\right)$ were detected, pointing out that these phases are mainly amorphous. Small diffraction peaks were also observed in sample MoC-SA-pH7 (using DCBS) at $\approx 9.5$, $\approx 14.5, \approx 16.1, \approx 27.2, \approx 32.7$ or $\approx 39.4^{\circ}$. These peaks can be due to the formation of sodium molybdate species, as reported by Wang et al. [39]. They used surfactants as unique carbon precursors and ammonium heptamolybdate as Mo-precursor to obtain $\beta-\mathrm{Mo}_{2} \mathrm{C}$. They obtained aggregates of $\beta-\mathrm{Mo}_{2} \mathrm{C}$ crystallites with different structures, from hollow rods to hollow spheres when using polyethylene glycol (PEG) or CTAB, respectively, and big platelets using DCBS. These platelet structures showed low surface and are contaminated by the formation of $\mathrm{Na}_{2} \mathrm{Mo}_{3} \mathrm{O}_{3}$ (JCPDS 28-1111) as impurity, related to the significant amount of $\mathrm{Na}^{+}$added as a counter-ion with the anionic surfactant [37]. 


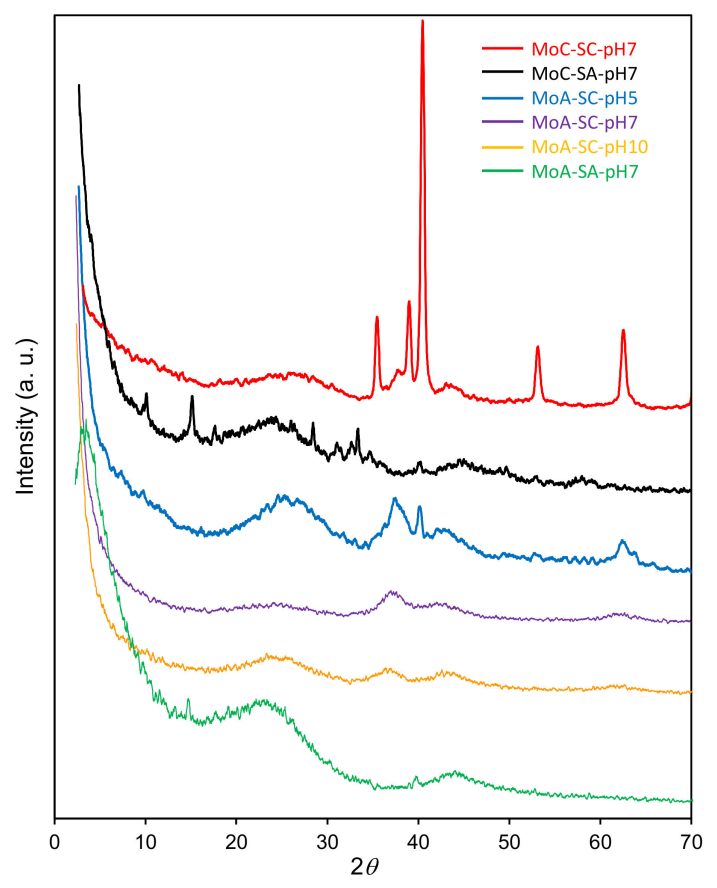

Figure 5. XRD-patterns of Mo-doped carbon xerogels.

XPS analyses of Mo-doped carbon xerogels were also performed and the C1s, O1s and Mo3d spectral regions were properly deconvoluted, as shown in Figure 6. The chemical surface composition of the different samples is summarized in Table 1, together with those corresponding organic precursors. The carbon content increases as the heteroatom content decreases (both $\mathrm{O}$ and $\mathrm{N}$ ) during carbonization because they are released as pyrolysis gases $\left(\mathrm{CO}_{\mathrm{x}}, \mathrm{NO}_{\mathrm{x}}\right)$. The metal content is also modified as a consequence of sintering or reaction with the organic phase. Analogously to the organic gels, a great difference in the metallic surface concentration present on carbon xerogels is obtained using the anionic surfactant regarding those obtained using the cationic one.

Figure 6 depicted the Mo3d region for carbon samples obtained with different combinations of anionic and cationic surfactants and metal precursors, the different chemical state of Mo in each sample being obvious at a glance. The Mo3d spectra of the MoA-SA-pH7 sample (both anionic surfactant and metal precursor, Figure $6 a$ ) was fitted using only a doublet, the peaks at $\approx 232.9$ and $\approx 236.0 \mathrm{eV}$ corresponding to the $\mathrm{d}_{5 / 2}$ and $\mathrm{d}_{3 / 2}$ components of $\mathrm{Mo}^{6+}$ in $\mathrm{MoO}_{3}$ [35], as previously described. The oxide should be mainly amorphous, taking into account the previous XRD (Figure 5). In the MoC-SA-pH7 sample (anionic surfactant and cationic $\mathrm{Mo}^{5+}$ precursor), the Mo spectra is more complex (Figure $6 \mathrm{~b}$ ). As described for the organic xerogels, the main peaks at $\approx 234.7$ and $\approx 237.3 \mathrm{eV}$ denote the formation of highly oxidized Mo-species. These $\mathrm{MoO}_{3}$ particles are in a more withdrawing environment than in MoA-SA-pH7, because the components of $\mathrm{Mo}^{6+}$ are shifted to significantly higher BE. The new peaks, not observed in the organic xerogels (Figure 1f), were located at $\approx 231.4$ and $\approx 234.4 \mathrm{eV}$ and assigned to the $\mathrm{d}_{5 / 2}$ and $\mathrm{d}_{3 / 2}$ signals of $\mathrm{Mo}^{5+}$, respectively [39]. Moreover, a small peak located at $\approx 228.3 \mathrm{eV}$ can be assigned to $\mathrm{Mo}^{2+}$ [40]. In the case of the MoA-SC-pH7 sample (Figure 6c), i.e., combining cationic surfactant and anionic Mo-precursor, the main peaks located at $\approx 233.0$ and $\approx 236.2 \mathrm{eV}$ showed that molybdenum remains as $\mathrm{Mo}^{6+}$ in $\mathrm{MoO}_{3}$, but in this case the peak at $\approx 228.4 \mathrm{eV}$ also confirms the $\mathrm{Mo}^{6+}$ reduction to $\mathrm{Mo}^{2+}$. The reduced Mo-fraction corresponds to a $10 \%$ of the total Mo-content observed. Finally, the combination of the cationic $\mathrm{Mo}^{5+}$ precursor with cationic surfactant (MoC-SC-pH7, Figure $6 \mathrm{~d}$ ) leads to a strong increase of the peak at $\approx 228.6 \mathrm{eV}$, denoting the significant reduction of Mo-phase to $\mathrm{Mo}^{2+}$ (reaching $60 \%$ of the total Mo-content observed). Although this peak can be associated with the presence of an intermediate oxide $\left(\mathrm{MoO}_{2}\right)$ [40], the obtained XRD patterns of this sample (Figure 5) provides unequivocal proof of the formation of $\beta-\mathrm{Mo}_{2} \mathrm{C}$ crystallites, thus the peak at $\approx 228.6 \mathrm{eV}$ can be assigned to $\mathrm{Mo}^{2+}$ in molybdenum carbide $\left(\mathrm{Mo}_{\mathrm{x}} \mathrm{C}\right)$; 
also in agreement with the literature $[39,41]$. Similar XPS spectra (not shown), were also detected for samples obtained at different $\mathrm{pH}$ (MoA-SC-pH10 and MoA-SC-pH5), $\mathrm{Mo}^{2+}$ and $\mathrm{Mo}^{6+}$ species being detected, although the proportion of $\mathrm{Mo}^{2+}$ changed from acidic media (37\%) to basic media $(43 \%)$. The Mo-reduction and the fraction of Mo-carbide formed strongly depend on the electrostatic interactions during polymerization that determine the nature of metallic-organic phase links and therefore, the transformations during carbonization.
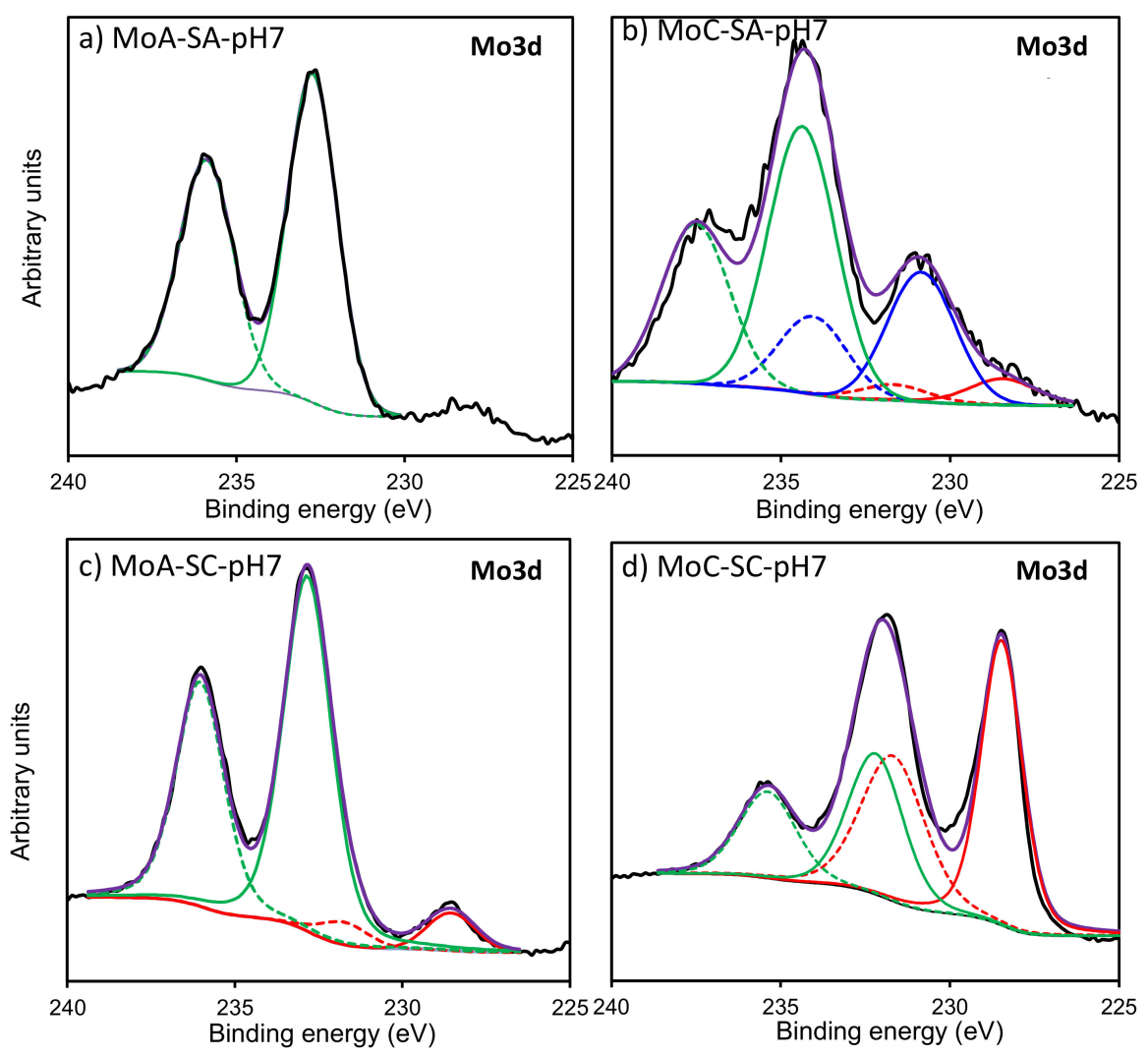

Figure 6. Influence of the combination of cationic and anionic surfactants and Mo-precursors on the distribution of Mo-species in the final Mo-doped carbon xerogels.

The shape, dimension and distribution of Mo-particles were analyzed by HRTEM. Representative HRTEM images of the Mo-doped carbon xerogels are shown in Figure 7. When both anionic DCBS and $\mathrm{MoO}_{4}{ }^{2-}$ (MoA-SA-pH7) are combined, the formation of big Mo-particles was observed together with a significant distribution of small nanoparticles (Figure 7a,b). These large particles present an ordered structure formed by the stacking of platelet particles, as previously described by Wang et al. [39]. The selected area electron diffraction (SAED, Figure $7 \mathrm{~b}$ inset) clearly showed a certain crystallinity, although it was not detected in XRD patterns (Figure 5). The formation of such large structures can be related with the low Mo-content detected by XPS and a poor porosity. When using $\mathrm{Mo}^{+5}$ (MoC-SA-pH7) needle shaped particles are formed instead of the platelet ones (Figure 7c-d), together at a good concentration of smaller nanoparticles. Using the CTAB surfactant, a high concentration of small homogeneously distributed Mo-nanoparticles is always observed (Figure 7e-h), independently of the morphology of the carbon supports, the nature of Mo-precursor or the $\mathrm{pH}$ value, which is also consistent with the XPS results. It is interesting to note that the carbon foam structure observed for MoA-SC-pH5 or the carbon filaments obtained in the case of MoA-SC-pH7 are highly coated with metallic nanoparticles (Figure 7e,g respectively). 


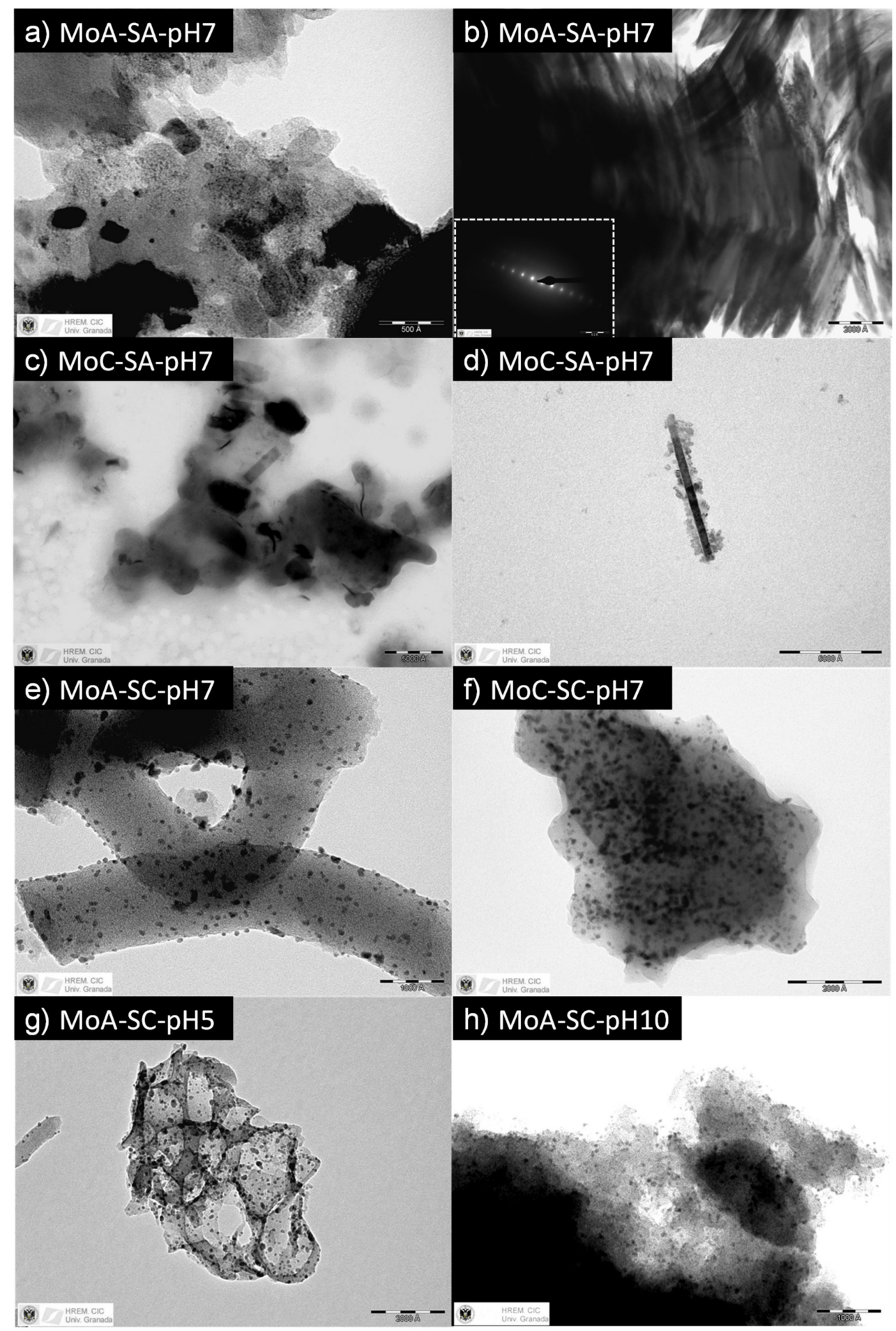

Figure 7. HRTEM images showing a high dispersion of metallic nanoparticles on the different carbon xerogels.

As summary, a scheme with all possible combinations concerning surfactants and metal precursors with the organic RF matrix is showed in Figure 8. Overall, both cationic and metal precursors are desirable because an enhanced porosity and Mo-reduction and dispersion are obtained in the final Mo-doped carbon xerogel. 


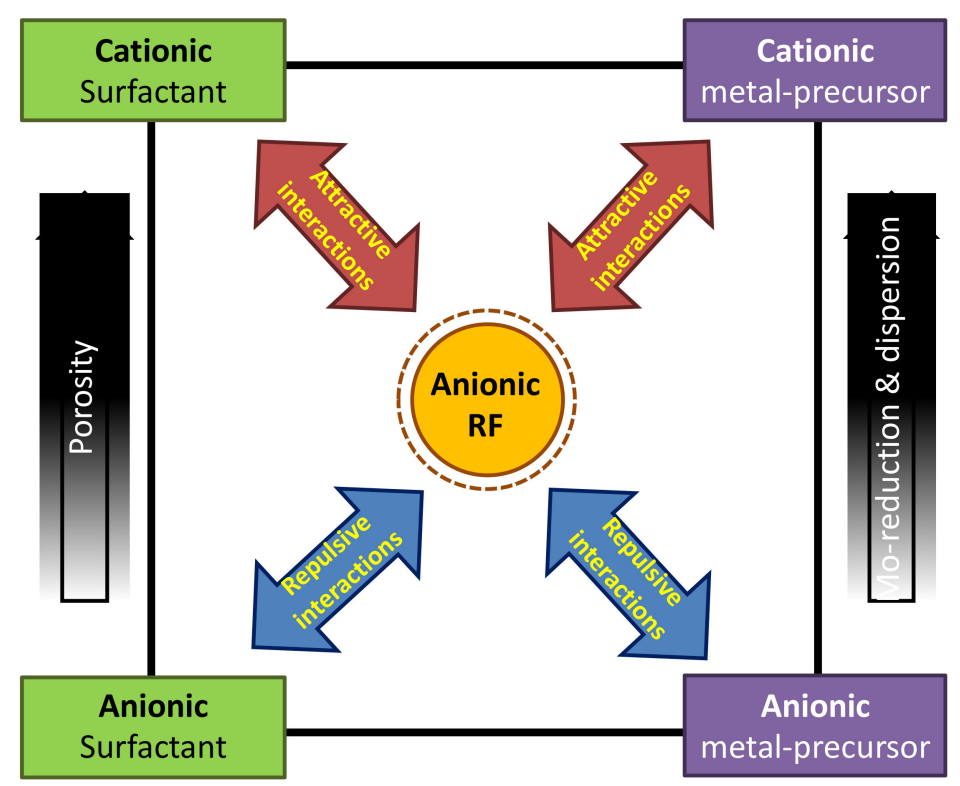

Figure 8. Scheme of the synthesis of Mo-doped carbon gels with special emphasis on the electrostatic interactions between surfactants, metal precursors and organic RF-matrix.

\section{Conclusions}

A series of Mo-doped carbon xerogels were prepared by modifying the synthesis process in such a manner that different types of electrostatic interactions can be established in the polymerizing solutions. For this purpose, the starting solutions of resorcinol-formaldehyde (R-F) monomers were modified with different combinations of cationic or anionic surfactants and cationic or anionic metal precursors. The starting $\mathrm{pH}$ of the solution was also fitted from acidic to basic conditions by adding $\mathrm{NaOH}$.

The importance of favoring attractive interactions between the negatively charged RF macromolecule growing during polymerization with the different components of the mixture can be concluded. Thus, the best results were obtained using both cationic surfactant and cationic metal precursors at around $\mathrm{pH}$ neutrality. In such conditions, the porosity is developed because of the incorporation of the surfactant into the chemical structure of the organic polymer, that it is decomposed thereafter at relatively low temperature. In addition, this fact provides new anchoring sites for the metallic species increasing the surface Mo-content. These bonds favor that Mo-species can also strongly interact with the organic phase, being reduced during carbonization and forming Mo-nanoparticles homogenously distributed on the carbon supports. The Mo-reduction and the formation of crystalline $\mathrm{Mo}_{2} \mathrm{C}$ are also favored in this sense.

On the contrary, the strongest repulsive interactions occur using anionic surfactant and anionic Mo-precursor. In this case, the porosity, the dispersion and reduction degree of the Mo-phases are scarce. Mo-phase remains as amorphous $\mathrm{MoO}_{3}$, due to the lack of interactions with the organic fraction. Despite that small Mo-nanoparticles are detected by HRTEM, the formation of large platelet metallic structures leads to lower surface metal content, which can limit the catalytic performance of these samples. Intermediate physicochemical properties were obtained for samples prepared by combining anionic and cationic species.

The samples present a wide variety of morphologies, from particulate spherical particles to continuous foam-like structures, normally coated with a high and homogeneous distribution of metallic nanoparticles in different oxidation states. Fitting the combination of charged species in the starting solution is clearly a good option to design metal-doped carbon xerogels with the desired characteristics for catalytic applications.

Supplementary Materials: The following are available online at http://www.mdpi.com/2227-9717/8/6/746/s1, Figure S1. Isotherms of $\mathrm{CO}_{2}$-adsorption: (a) influence of $\mathrm{pH}$ and (b) influence of the surfactant nature. 
Author Contributions: Conceptualization, F.J.M.-H.; investigation, H.J., L.M.P.-M. and S.M.-T.; writing-original draft preparation, F.J.M.-H.; writing—review and editing, S.M.-T. and L.M.P.-M.; supervision, F.J.M.-H.; funding acquisition, F.J.M.-H. and S.M.-T. All authors have read and agreed to the published version of the manuscript.

Funding: This work was financially supported by the Spanish Project ref. RTI2018-099224-B-I00 from ERDF/Ministry of Science, Innovation and Universities-State Research Agency.

Acknowledgments: S.M.-T. and LM.P.-M. acknowledge the University of Granada (Reincorporación Plan Propio) and the Spanish Ministry of Economy and Competitiveness (MINECO) for a Ramón y Cajal research contract (RYC-2016-19347), respectively.

Conflicts of Interest: The authors declare no conflict of interest.

\section{References}

1. Mączka, M.; Pasierb, P. Sol-gel synthesis of metal (V, W, Zn) oxide-Carbon nanocomposites as cathode materials for Al-ion batteries. Ceram. Int. 2019, 45, 11041-11049. [CrossRef]

2. Demirci, S.; Dikici, T.; Tünçay, M.; Kaya, N. A study of heating rate effect on the photocatalytic performances of $\mathrm{ZnO}$ powders prepared by sol-gel route: Their kinetic and thermodynamic studies. Appl. Surf. Sci. 2020, 507, 145083. [CrossRef]

3. Neščáková, Z.; Zheng, K.; Liverani, L.; Nawaz, Q.; Galusková, D.; Kaňková, H.; Michálek, M.; Galusek, D.; Boccaccini, A.R. Multifunctional zinc ion doped sol-gel derived mesoporous bioactive glass nanoparticles for biomedical applications. Bioactive Mater. 2019, 4, 312-321. [CrossRef] [PubMed]

4. Seraji, M.M.; Kianersi, S.K.; Hosseini, S.H.; Davarpanah, J.; Elahi, S. Performance evaluation of glass and rock wool fibers to improve thermal stability and mechanical strength of monolithic phenol-formaldehyde based carbon aerogels. J. Non-Cryst. Solids 2018, 491, 89-97. [CrossRef]

5. Cheng, H.; Xue, H.; Hong, C.; Zhang, X. Preparation, mechanical, thermal and ablative properties of lightweight needled carbon fibre felt/phenolic resin aerogel composite with a bird's nest structure. Compos. Sci. Technol. 2017, 140, 63-72. [CrossRef]

6. Sanchez-Sancheza, A.; Izquierdo, M.T.; Medjahdi, G.; Ghanbaja, J.; Celzard, A.; Fierro, V. Ordered mesoporous carbons obtained by soft-templating of tannin in mild conditions. Microporous Mesoporous Mater. 2018, 270, 127-139. [CrossRef]

7. Qian, M.; Wang, Z.; Li, Z.; Xu, J.; Sun, P.; Lin, J.; Lin, T.; Huang, F. Sol-gel assisted chemical activation for nitrogen doped porous carbon. Microporous Mesoporous Mater. 2019, 286, 18-24. [CrossRef]

8. Pekala, R.W. Organic aerogels from the polycondensation of resorcinol with formaldehyde. J. Mater. Sci. 1989, 24, 3221-3227. [CrossRef]

9. Lin, C.; Ritter, J.A. Effect of synthesis $\mathrm{pH}$ on the structure of carbon xerogels. Carbon 1997, 35, 1271-1278. [CrossRef]

10. Al-Muhtaseb, S.A.; Ritter, J.A. Preparation and Properties of Resorcinol-Formaldehyde Organic and Carbon Gels. Adv. Mater. 2003, 15, 101-114. [CrossRef]

11. Laskowski, J.; Milow, B.; Ratke, L. Subcritically dried resorcinol-formaldehyde aerogels from a base-acid catalyzed synthesis route. Microporous Mesoporous Mater. 2014, 197, 308-315. [CrossRef]

12. Mulik, S.; Sotiriou-Leventis, C. Aerogels Handbook-Advances in Sol-Gel Derived Materials and Technologies; Aegerter, M.A., Leventis, L., Koebel, M.M., Eds.; Springer: New York, NY, USA; Dordrecht, The Netherlands; Berlin/Heidelberg, Germany; London, UK, 2011; pp. 215-234, Chapter 11.

13. Tonanon, N.; Tanthapanichakoon, W.; Yamamoto, T.; Nishihara, H.; Mukai, S.R.; Tamon, H. Influence of surfactants on porous properties of carbon cryogels prepared by sol-gel polycondensation of resorcinol and formaldehyde. Carbon 2003, 41, 2981-2990. [CrossRef]

14. Liu, D.; Lei, J.-H.; Guo, L.-P.; Qu, D.; Li, Y.; Su, B.-L. One-pot aqueous route to synthesize highly ordered cubic and hexagonal mesoporous carbons from resorcinol and hexamine. Carbon 2012, 50, 476-487. [CrossRef]

15. Matos, I.; Fernandes, S.; Guerreiro, L.; Barata, S.; Ramos, A.M.; Vital, J.; Fonseca, I.M. The effect of surfactants on the porosity of carbon xerogels. Microporous Mesoporous Mater. 2006, 92, 38-46. [CrossRef]

16. Maldonado-Hódar, F.J.; Jirglová, H.; Pérez-Cadenas, A.F.; Morales-Torres, S. Chemical control of the characteristics of Mo-doped carbon xerogels by surfactant-mediated synthesis. Carbon 2013, 51, 213-223. 
17. Maldonado-Hódar, F.J.; Jirglová, H.; Morales-Torres, S.; Pérez-Cadenas, A.F. Influence of surfactants on the physicochemical properties and catalytic behaviour of Mo-doped carbon xerogels. Catal. Today 2018, 301, 217-225.

18. Patel, V.; Ray, D.; Aswal, V.K.; Bahadur, P. Triton X-100 micelles modulated by solubilized cinnamic acid analogues: The pH dependent micellar growth. Colloids Surf. A 2014, 450, 106-114. [CrossRef]

19. Llombarta, P.; Palafox, M.A.; MacDowell, L.G.; Noya, E.G. Structural transitions and bilayer formation of CTAB aggregates. Colloids Surf. A 2019, 580, 123730. [CrossRef]

20. Kiciński, W.; Dziura, A. Heteroatom-doped carbon gels from phenols and heterocyclic aldehydes: Sulfur-doped carbon xerogels. Carbon 2014, 75, 56-67. [CrossRef]

21. Alegre, C.; Sebastián, D.; Gálvez, M.E.; Moliner, R.; Lázaro, M.J. Sulfurized carbon xerogels as Pt support with enhanced activity for fuel cell applications. Appl. Catal. B 2016, 192, 260-267. [CrossRef]

22. Maldonado Hódar, F.J.; Jirglová, H.; Perez Cadenas, A.F. Method for Obtaining Doped Carbon Gels, Gels Thus Obtained and Use Thereof as Catalysts. World Intellectual Property Organization Patent WO 2012/164128 A2, 6 December 2012.

23. Padilla-Serrano, M.N.; Maldonado-Hódar, F.J.; Moreno-Castilla, C. Influence of Pt particle size on catalytic combustion of xylenes on carbon aerogel-supported Pt catalysts. Appl. Catal. B 2005, 61, 253-258. [CrossRef]

24. Bailón-García, E.; Elmouwahidi, A.; Ribeiro, F.; Henriques, C.; Pérez-Cadenas, A.F.; Carrasco-Marín, F.; Maldonado-Hódar, F.J. Reduction of NO with new vanadium-carbon xerogel composites. Effect of the oxidation state of vanadium species. Carbon 2020, 156, 194-204. [CrossRef]

25. Maldonado-Hódar, F.J.; Moreno-Castilla, C.; Rivera-Utrilla, J.; Ferro-García, M.A. Metal-carbon aerogels as catalysts and catalyst supports. Stud. Surf. Sci. Catal. 2000, 130, 1007-1012.

26. Morales-Torres, S.; Maldonado-Hódar, F.J.; Pérez-Cadenas, A.F.; Carrasco-Marín, F. Textural and mechanical characteristics of carbon aerogels synthesized by polymerization of resorcinol and formaldehyde using alkali carbonates as basification agents. Phys. Chem. Chem. Phys. 2010, 12, 10365-10372. [CrossRef]

27. Rahem, R.A. The influence of hydrophobic counterions on micellar growth of ionic surfactants. Adv. Colloid Interface Sci. 2008, 141, 24-36. [CrossRef]

28. Maldonado-Hódar, F.J.; Moreno-Castilla, C.; Rivera-Utrilla, J.; Hanzawa, Y.; Yamada, Y. Catalytic graphitization of carbon aerogels by transition metals. Langmuir 2000, 16, 4367-4373. [CrossRef]

29. Dominguez Garcia, E.; Chen, J.; Oliviero, E.; Oliviero, L.; Maugé, F. New insight into the support effect on HDS catalysts: Evidence for the role of Mo-support interaction on the $\mathrm{MoS}_{2}$ slab morphology. Appl. Catal. B 2020, 260, 117975. [CrossRef]

30. Wen, Y.; Zhu, H.; Zhang, L.; Zhang, S.; Zhang, M.; Du, M. Activating $\mathrm{MoS}_{2}$ by interface engineering for efficient hydrogen evolution catalysis. Mater. Res. Bull. 2019, 112, 46-52. [CrossRef]

31. Bansal, R.C.; Donnet, J.B.; Stoeckli, F. Active Carbon; Marcel Dekker: New York, NY, USA, 1988.

32. Perez-Cadenas, A.F.; Maldonado-Hodar, F.J.; Moreno-Castilla, C. On the nature of surface acid sites of chlorinated activated carbons. Carbon 2003, 41, 473-478. [CrossRef]

33. Reddy, B.M.; Chowdhury, B.; Reddy, E.P.; Fernández, A. An XPS study of dispersion and chemical state of $\mathrm{MoO}_{3}$ on $\mathrm{Al}_{2} \mathrm{O}_{3}-\mathrm{TiO}_{2}$ binary oxide support. Appl. Catal. A 2001, 213, 279-288. [CrossRef]

34. Pérez-Cadenas, M.; Moreno-Castilla, C.; Carrasco-Marín, F.; Pérez-Cadenas, A.F. Surface Chemistry, Porous Texture, and Morphology of N-Doped Carbon Xerogels. Langmuir 2009, 25, 466-470. [CrossRef] [PubMed]

35. Wang, H.; Wang, Z.; Chen, S. Preparation of molybdenum carbides with multiple morphologies using surfactants as carbon sources. J. Solid State Chem. 2012, 194, 19-22. [CrossRef]

36. White, R.T.; Thibau, E.S.; Lu, Z.-H. Interface Structure of $\mathrm{MoO}_{3}$ on Organic Semiconductors. Sci. Rep. 2016, 6, 21109. [CrossRef] [PubMed]

37. Cazorla-Amoros, D.; Alcañiz-Monge, J.; Linares-Solano, A. Characterization of activated carbon fibers by $\mathrm{CO}_{2}$ adsorption. Langmuir 1996, 12, 2820-2824. [CrossRef]

38. Job, N.; Pirard, R.; Marien, J.; Pirard, J.P. Synthesis of transition metal-doped carbon xerogels by solubilization of metal salts in resorcinol-formaldehyde aqueous solution. Carbon 2004, 42, 3217-3227. [CrossRef]

39. Wang, P.; Qi, J.; Chen, X.; Li, C.; Wang, T.; Liang, C. New insights into high-valence state Mo in molybdenum carbide nanobelts for hydrogen evolution reaction. Int. J. Hydrog. Energy 2017, 42, 10880. [CrossRef] 
40. Zhuang, R.; Yao, S.; Shena, X.; Li, T. Hydrothermal synthesis of mesoporous $\mathrm{MoO}_{2}$ nanospheres as sulfur matrix for lithium sulfur battery. J. Electroanal. Chem. 2019, 833, 441-448. [CrossRef]

41. Bravo-Sanchez, M.; Romero-Galarza, A.; Ramírez, J.; Gutiérrez-Alejandre, A.; Solís-Casados, D.A. Quantification of the sulfidation extent of Mo in CoMo HDS catalyst through XPS. Appl. Surf. Sci. 2019, 493, 587-592. [CrossRef] 